\title{
Health related quality of life of stroke survivors in Africa: a critical review of literature
}

\author{
Umaru Muhammad Badaruํㅜ, Omoyemi Olubunmi Ogwumike², Ade Fatai Adeniyi ${ }^{2}$ \\ ${ }^{1}$ Department of Physiotherapy, Faculty of Allied Health Sciences, Bayero University, Kano, Nigeria \\ ${ }^{2}$ Department of Physiotherapy, College of Medicine, University of Ibadan, Ibadan, Nigeria
}

\begin{abstract}
Stroke care is aimed at improving physical, functional, psychological and social function and to eventually improve the overall health related quality of life (HRQOL). This paper critically reviewed published papers that reported on stroke survivors' HRQOL and the factors associated with it from the African region.

A total of 19 articles met the inclusion criteria for the review and majority of them $12(63 \%)$ are cross-sectional surveys. In Africa, HRQOL deteriorated significantly after stroke. The reported mean score of HRQOL ranges from below $50 \%$ to slightly below $70 \%$. Severity of stroke related symptoms, impairment of physical function, and depression were the most important factors determining HRQOL. However, the influence of social function on HRQOL needs further study. The Studies have shown that stroke rehabilitation in Africa leads to significant improvement HRQOL.

Finally, this review has highlighted some critical areas of HRQOL in which the intending African researcher needs examined adequately.
\end{abstract}

Keywords: Stroke Survivor, Africa, Health related quality of life

\section{Introduction}

Stroke is a sudden life shattering event [1,2] which usually leaves affected individual and the caregivers inadequately prepared to handle its consequences [1]. Advances in stroke care have led to the increase in the number of people who survived stroke but had to live with long term disabilities. Health should be assessed not only on the basis of saving lives, but also in terms of improving their quality [3]. Hence effective stroke management should be designed to protect health, prolong biological lives, and improve quality of life (QOL) [4]. The Paradigm shift in stroke care is to "add years to biological life" and "add life to biological years" $[4,5]$.

The term QOL has meaning in almost all the educational disciplines and can therefore be define in different ways [3]. This made it a broad concept with different political, philosophical and health linked meanings [6]. The reasons for the extensive meanings attached to QOL is that it can be affected in a complex way by the individuals' present health states (physical, psychological and functional), social relationships, personal beliefs, the environment [7] and financial status [8]. It is broadly defined as: "the individuals' perception of their position in life in the context of the culture and value systems in which they live and in relation to their goals, expectations, standards and concerns"[7].

The health-related Quality of life (HRQOL) concept though narrower and more focused than QOL, still needs to assess multiple dimensions of life [9]. HRQOL is a health-focused HRQOL model that assesses aspects of QOL that is affected by the variations in health states [10]. The HRQOL of life is therefore the total effect of individual and environmental factors on function and health status and includes physical, psychological and social functions [11]. 
Stroke causes a decrease in HRQOL $[12,13]$. This reduction is pronounced, even among survivors who have none or very minimal post stroke disability [14]. Therefore stroke care is aimed at improving physical, functional, psychological and social functions of survivors and to eventually improve HRQOL. As the culture and the value system of communities differ, so also would be the factors that could influence the HRQOL of people in a particular community. Knowing the factors that are specifically related to HRQOL of survivors from low income third world nations of Africa is very important for public health issues. It is therefore essential to understand the extent to which stroke related factors and other environmental factors affects HRQOL of African survivors.

This paper critically reviewed published papers that reported on survivors HRQOL and the factors associated with it from the African point of view in order to make comparison with what is obtained around the world. This review hopes to guide the intending African researcher on the critical areas of HRQOL of stroke survivors that needs to be examined adequately.

\section{Methodology}

Literatures were searched through citation tracking, free browsing in Google, Google Scholar and African journals online using the key search terms 'quality of life stroke Africa, "health related quality of life stroke Africa 'determinants quality of life stroke Africa,' We also interchanged 'Africa' with the names of different African countries. The inclusion criteria for the review include: access to full length of the article, the HRQOL assessed must be that of a stroke survivor, the study participants must be Africans and the HRQOL must be assessed using a validated instrument.

\section{Description of the included studies}

A total of 19 articles met the inclusion criteria for the review. Twelve (63\%) of the included studies were cross-sectional surveys and 7(37\%) were longitudinal (follow up studies). The studies were published between 2008 and 2014. The detailed description of the included studies is in table 1 .

\section{Socio-demographic characteristics of participants in the included studies}

In this review, the 19 included studies assessed the HRQOL of a total of 1797 stroke survivors which comprised $932(51.9 \%)$ males and 865 (48.1\%) females. The reported mean age of the stroke survivors range from 44.5years [49] to 67.1 years [18]. Although some of the included studies $[13,15,18,19,23,49]$ did not report the survivors' stroke types, the status of 1216 stroke survivors which consist of 568 (46.7\%) ischemic stroke, $298(24.5 \%)$ hemorrhagic stroke and 350(28.8\%) indeterminate cases have been reported. This implies that majority of African stroke survivors are males and most of them suffered ischemic stroke. 
Table 1: Studies on quality of life of stroke survivors in Africa

\begin{tabular}{|c|c|c|}
\hline Authors & Design & Results \\
\hline Akosile et al, 2013 & CSS & $\begin{array}{l}\text { Overall QOL score was slightly below } 70 \% \text {. There was no significant sex difference } \\
\text { in QOL. QOL is most affected in the social role domain }\end{array}$ \\
\hline Owolabi, 2011 & CSS & $\begin{array}{l}\text { SSV significantly had worse HRQOL than AHAs in domains within the physical } \\
\text { sphere while domains in the spiritual sphere are stroke-resilient. }\end{array}$ \\
\hline Hamza et al, 2014 & LS & $\begin{array}{l}\text { Motor impairment, disability and depression were independent predictors of } \\
\text { HRQoL. There was improvement in domains of SIS except emotion domain }\end{array}$ \\
\hline Owolabi 2013 & CSS & $\begin{array}{l}\text { Stroke severity, disability, emotional disorder, and sense of purpose in life were the } \\
\text { key predictors of HRQOL after stroke. }\end{array}$ \\
\hline Gbiri and Akinpelu, 2012 & LS & $\begin{array}{l}\text { QoL improved significantly from onset to } 6 \text { months. Depression was a major } \\
\text { determinant of QoL. }\end{array}$ \\
\hline Owolabi, 2008 & CSS & $\begin{array}{l}\text { Determinants of HRQOL were stroke severity, disability, social support, laughter and } \\
\text { negative feelings and social support determine }\end{array}$ \\
\hline Abubakar and Isezuo, 2012 & CSS & $\begin{array}{l}29 \% \text { of the SSV were depressed and } 54.8 \% \text { had good recovery. Function status and } \\
\text { depression independently determined poor HRQoL. }\end{array}$ \\
\hline Hamzat and Peters, 2009 & LS & $\begin{array}{l}\text { Motor function increased }(\mathrm{P}<0.05) \text { in the first to sixth month post-stroke. No } \\
\text { significant correlation was observed between motor function and QoL }\end{array}$ \\
\hline Gbiri et al, 2010 & LS & $\begin{array}{l}\text { The QoL post stroke was significantly influenced by depression, age, marital status, } \\
\text { spouse supports, stroke-severity, and educational-attainment }\end{array}$ \\
\hline Akinpelu and Gbiri 2009 & CSS & $\begin{array}{l}\text { Both Objective ( } 42 \pm 12.8) \text { and Subjective QoL of SSV }(67.8 \pm 10.6) \text { were significantly } \\
\text { lower than that of the AHA }\end{array}$ \\
\hline Owolabi 2010 & CSS & $\begin{array}{l}\text { The consistent independent predictors of generic and stroke-specific HRQOL } \\
\text { were stroke severity, disability, laughter and negative-feeling frequencies. }\end{array}$ \\
\hline Rhoda 2014 & LS & Functional ability and urinary incontinence were the factors affecting QOL. \\
\hline Kamel et al, 2010 & LS & $\begin{array}{l}\text { Scores of SIS improved at } 3 \text { months. The SIS score was affected by severity of } \\
\text { disability, impairment and moderate-severe depression. }\end{array}$ \\
\hline Howitt et al, 2011 & CSS & $\begin{array}{l}\text { SSV have lower QOL than controls. Poorer QOL was associated with physical dis- } \\
\text { ability, anxiety, depression and reduced social interaction. }\end{array}$ \\
\hline Muli and Rhoda, 2013 & CSS & $\begin{array}{l}\text { The mean QOL scores, ranged from } 30 \% \text { to } 48 \% \text {. Males had higher QOL scores than } \\
\text { females in all the domains except in physical functioning. }\end{array}$ \\
\hline Donkor, 2014 & CSS & $\begin{array}{l}\text { The controls had higher HRQOL than the SSV. Determinants of HRQOL are age, } \\
\text { stroke severity and negative emotions, post-stroke duration and stroke recurrence }\end{array}$ \\
\hline Assogba et al, 2011 & CSS & $\begin{array}{l}\text { QOL deteriorated an average of } 0.94 \text {. Disability, anxiety and depression all affect } \\
\text { the QOL. }\end{array}$ \\
\hline Akinpelu et al, 2012 & CSS & $\begin{array}{l}\text { The mean QoL scores varied between } 45 \% \text { and } 53 \% \text { in all domains and poor in the } \\
\text { environment domain } 28 \% \text {. Comobidity influenced QoL among male SSV }\end{array}$ \\
\hline Gbiri and Akinpelu 2013 & LS & $\begin{array}{l}\text { Mean QoL and mean functional performance increased significantly. Functional } \\
\text { recovery had significant direct relationship with QoL. }\end{array}$ \\
\hline
\end{tabular}

QoL=Quality of life; HRQOL=health related quality of life; SSV=stroke survivor; AHA=Apparently healthy adults; $\mathrm{CSS}=$ cross-sectional survey; LS=longitudinal study 


\section{Medical and rehabilitation services received by} African stroke survivors

The participants received physiotherapy [13, $15,16,17,18,19,20,21,22]$ emergency medical services $[17,20]$, routine medical services $[16$, 23], occupational therapy [13], and speech therapy [13]. This therefore implies that physiotherapy plays a vital role in stroke rehabilitation in Africa. However, only the study by Gbiri and Akinpelu [21] gave the frequency of the physiotherapy program rendered. They [21] were able to mention the specific neurological physiotherapy approach used in the rehabilitation of the survivors. Therefore, explaining the details to treatment will help to highlight the extent and standard of care given to the survivors.

\section{The HRQOL of stroke survivors in Africa}

According to de Haan, et al [24] HRQOL should comprise at least four domains the physical health, functional health, psychological health and the social functioning [24]. This review is guided by Wilson and Cleary HRQOL model [25] and the HRQOL dimensions reported in de Haan, et al [24].

\section{Physical health}

This comprised treatment or disease related symptoms [24]. In this review severity of stroke related symptoms and impairments were shown to adversely affect HRQOL of African stroke survivors[2, 17, 22, 26, 27, 28, 9]. Importantly the included studies were able to exclude stroke survivors suffering from other life chronic threatening conditions not directly related to stroke that may concurrently impact on their HRQOL of such as cancers[16], brain tumors [13], stroke-like symptom due to previous head injury [13], heart failure [2,29], peritoneal or hemodialysis [2, 29] and active psychiatric disease [2].

\section{Psychological health}

The psychological health includes emotional status and cognitive functioning [24]. Presence of emotional symptoms such as anxiety [30] or Depression adversely affects HRQOL [30, 31, 32, $33,34,35]$ more than the impairment of physical function [33] because depression negatively influence physical function[34]. Furthermore, stroke leads to substantial deterioration of cognitive function [36] and impaired cognitive function have negative influence on HRQOL [37, 38].

\section{Emotional status of African stroke survivors}

In this review, 29\% [39] to $85 \%$ [20] of stroke survivors in Africa were reported to have experienced symptoms of depression. The depression status ranges from mild mood disturbance [29] to severe depression [20]. It is important to note that majority of the included studies did not adequately report the emotional status of stroke survivors that is, for example most of them failed to explain the number of the survivors that were depressed and the severity of the emotional disorder the among the study participants. Sufficient knowledge the emotional status of study participants will help researchers to adequately explain the impact of impairment of psychological function on HRQOL.

\section{Relationship between emotional status and HRQOL of stroke survivors in Africa}

In-line with what obtains in other regions of the world, depression was the most important emotional symptom that influences HRQOL of stroke survivors in Africa [2,17,18,20,39,40,29]. Furthermore, anxiety $[18,40]$ and other negative emotions for instance fear despair and anger $[22,26,27]$ have also adversely influenced the HRQOL of stroke survivors' life in Africa. 
Influence of Cognitive impairment on HRQOL of stroke survivors in Africa

To date only one African study conducted by Fatoye et al [38] assessed the influence of cognitive impairment on HRQOL stroke survivors. African researchers need to adequately assess cognitive function post stroke with the view to initiate early rehabilitation of cognitive impairment in order to improve HRQOL.

\section{Functional Health}

Functional health domain includes mobility selfcare and level of physical activity [24]. Studies have shown that impairment of physical function post stroke adversely affects HRQOL [30, 31, 35, 40].

\section{Functional status of stroke survivors in Africa}

In this review as presented in table 2, majority of the stroke survivors in Africa suffered mind to moderate disabilities and most of them can walk independently. It is worth mentioning that stroke rehabilitation in Africa lead to significant improvement of the survivors' functional status $[16,21,29,39]$.

\section{Influence of functional status on HRQOL of stroke} survivors in Africa

Impairment of physical function was one of the most important determinants HRQOL of stroke survivors in Africa. In this review physical disability $[2,18,26,27,28,29,40]$ and functional ability[13,21,39] were reported to have significant influence on HRQOL of stroke survivors in Africa. Furthermore, longitudinal African studies found that recovery of physical function leads to improved HRQOL post stroke [2, 20, 29] although one longitudinal study [16] found a differing result. 
Table 2: levels of functional ability/disabilities of the participants in the included studies

\begin{tabular}{|c|c|c|c|c|c|c|}
\hline & \multirow{2}{*}{$\begin{array}{l}\text { fully dependent/ } \\
\text { mild-moderate } \\
\text { help }\end{array}$} & \multirow{2}{*}{ Independent } & \multicolumn{4}{|c|}{ Disability } \\
\hline & & & None & Mild & moderate & $\begin{array}{l}\text { Moderately } \\
\text { Severe to } \\
\text { severe }\end{array}$ \\
\hline Owolabi 2011 & & & 16 & 27 & 24 & 33 \\
\hline Hamza et al, 2014 & \multicolumn{2}{|c|}{$\begin{array}{l}\text { Barthel index score }=60.5 \text { at six month } \\
\text { and } 68.5 \text { at } 1 \text { year }\end{array}$} & \multicolumn{4}{|c|}{$\begin{array}{l}\text { Mean disability score }=3.3 \text { at } 3 \text { months and } 3.1 \text { at } 1 \\
\text { year. }\end{array}$} \\
\hline Assogba et al, 2011 & & & 30 & 44 & 36 & 4 \\
\hline Owolabi , 2013 & & & 16 & 27 & 24 & 33 \\
\hline Owolabi, 2008 & 19 & 81 & 16 & 27 & 24 & 33 \\
\hline Akinpelu et al, 2012 & & & - & 34 & 21 & 20 \\
\hline Owolabi 2010 & 18 & 82 & 16 & 27 & 35 & 22 \\
\hline Gbiri et al, 2010 & & & & & 26 & 39 \\
\hline Donkor et al, 2014 & & & & 82 & 55 & 19 \\
\hline Akinpelu and Gbiri 2009 & \multicolumn{2}{|c|}{ motor performance $=55.3 \%$} & & & & \\
\hline Howit et al 2011 & 27 & 31 & & & & \\
\hline Rhoda 2014 & \multicolumn{2}{|c|}{ Barthel index score $=78.6 \pm 23.7$} & & & & \\
\hline Gbiri and Akinpelu, 2012 & 37 & 18 & & & & \\
\hline Total & $\begin{array}{c}101 \\
(32.3 \%)\end{array}$ & $\begin{array}{c}212 \\
(67.7 \%)\end{array}$ & $\begin{array}{c}94 \\
(11.6 \%)\end{array}$ & $\begin{array}{c}268 \\
(33.1 \%)\end{array}$ & $\begin{array}{c}245 \\
(30.2 \%)\end{array}$ & $\begin{array}{l}203 \\
(25 \%)\end{array}$ \\
\hline Grand total & \multicolumn{2}{|c|}{$313(100 \%)$} & \multicolumn{4}{|c|}{$810(100 \%)$} \\
\hline
\end{tabular}

\section{Social function}

This involves the assessment of the levels of social contacts and interactions [24]. The psychological and physical consequences of stroke may lead to a decrease in the survivors' level of social function [33, 42]. Social interaction was shown to improve experimental stroke outcome by increasing neural cell proliferation (neurogenesis) [43]. It also impacts on survivors' HRQOL [33]. According to Levasseur et al [44] social participation involves interpersonal relationships, responsibilities and recreation. 
Social function and HRQOL of African stroke survivors

The study by Akosile et al [23] revealed that the social role domain of HRQOL was the most severely affected post stroke, but there was no adequate description of the types of social activities affected. To date only the study by Howitt et al [18] reported that reduced social interaction was associated with poorer HRQOL. The authors [18] found that many of the survivors were unable to attend social function (markets, church). Intending researcher should therefore endeavor to give the details of how stroke event interfere with the different social activities of the stroke survivor so as to be able to adequately explain the associations of reduced social function post stroke and HRQOL.

\section{The environmental factors}

\section{Social support}

Social support can be instrumental emotional, or informational [45]. Studies have shown that social support is a determinant of HRQOL [31, 41, 34, 45]. Furthermore, a review by Reblin and Uchino [46] opinedGo to: that adequate social and emotional support can be protective to health.

Social support and HRQOL of stroke survivors in Arica

African studies have shown that social support [26] and spousal support [17,20] are determinants of HRQOL of stroke survivors. However, the specific areas were social supports were given to stroke survivors were not adequately explained. African researchers should adequately assessed sources of physical, emotional, instrumental and informational support in order to adequately explain social support in relation to HRQOL post stroke.

\section{Economic factors}

In this review only 3 of the articles reported on the stroke survivors' monthly income $[22,27,29]$ and they revealed that majority of African survivors earn low monthly incomes. Importantly, ability to return to work will help survivors' to earn some income which may better their QOL. According to Akinpelu and Gbiri [15] only $15 \%$ of the survivors were able to return to work, and in another study [18], about $65 \%$ gave up work permanently. This means that most stroke survivors in Africa earn low income prestroke and suffer inability to earn income post stroke which may negatively affect their HRQOL.

The observation is that most of the studies included in the review did not report on the income of the survivors and how it is affected by stroke which may have bearing on survivors' HRQOL. Furthermore, only one study reported on the sources of financial support especially for therapy and medication [29]. Adequacy of financial support for stroke survivors may have implication on their HRQOL and should therefore be assessed.

\section{Patient related factors}

Studies have shown that HRQOL is influenced by self-efficacy [47], motivation to perform selfcare activity [35]. It is worth mentioning that characteristic of the survivors such as preferences, level of motivation, and self-efficacy have rarely been studied in relation to HRQOL of stroke survivors in Africa.

\section{The overall HRQOL of life of stroke survivors in Africa}

Researches from Africa have shown that the HRQOL of stroke survivors deteriorated significantly after stroke [15,18,19,22,40,48,49]. It was also observed that African stroke survivors experienced poorer HRQOL than healthy persons $[48,15,18,22]$. The mean score of HRQOL ranges from below 50\% [49] to slightly below $70 \%[19,23]$. Finally studies have shown that stroke rehabilitation in Africa leads to significant improvement in HRQOL of survivors [2, 20, 21, 29] 


\section{Conclusion}

HRQOL of African stroke survivors deteriorated significantly after stroke. Stroke severity, impairment of physical function and depression were the most important factors determining HRQOL. The influence of social function, environmental factors and patient related factors on HRQOL of survivors in the continent needs further study. Physiotherapy plays a vital role in stroke rehabilitation in Africa. Stroke rehabilitation in the region leads to significant improvement HRQOL of survivors.

\section{Reference:}

1. Mayo NE, Wood-Dauphinee S, Ahmed S, Gordon C, Higgins J, McEwen S, Salbach N. Disablement following stroke. Disabil Rehabil. 1999; 21: 258-68.

2. Kamel A, Ghani AA, Zaiton MA, El-Motayam AS, El-Fattah DA. Health Related Quality of Life in Stroke Survivors Measured by the Stroke Impact Scale. Egypt J Neurol Psychiat Neurosurg. 2010; 47 (2): 267-273.

3. Center for Disease Control and Prevention. HRQOL Concepts. [Internet] 2011. [updated 2015 August 16. Available from:http://www.cdc. gov/hrqol/concept.html

4. Owolabi MO. Health-Related Quality of Life Measures: There are Still Many Unanswered Questions about Human Life. ScientificWorldJournal. 2008; 8:357-363.

5. Van den Bos, GAM, Triemstra AHM. Quality of life as an instrument for need assessment and outcome assessment of health care in chronic patients. Qual. Health Care. 1999; 8:247-252.

6. Fallowfield L. What is quality of life? London: Hayward Medical Communications, [Internet] 2009. Available from: http://www.medicine. ox.ac.uk/bandolier/painres/download/whatis/ WhatisQOL.pdf.

7. World Health Organization Quality of Life Assessment (WHOQOL). Position paper from the World Health Organization. Soc Sci Med. 1995; 41:1403-9.

8. Guyatt GH. Measurement of Health-Related Quality of Life in Heart Failure. J Am Coll Cardiol. 1993; 22 (4) (supplement A).
9. Jette AM. Using health-related quality of life measures in physical therapy outcomes research. PhysTher. 1993; 73: 528-537.

10. McHorney, CA. Health status assessment methods for adults: past accomplishments and future challenges. Annu Rev Public Health 1999; 20:309-335.

11. O'Sullivan, SB. Clinical Decision Making In: O'Sullivan, SB and Schmitz, TJ.. Physical Rehabilitation $5^{\text {th }}$ ed. New Delhi; Jay pee Brothers: 2007, PP 9.

12. Dhamoon MS, Moon YP, Paik MC, Boden-Albala B, Rundek T, Sacco RL, Elkind MSV Quality of life declines after first ischemic stroke (The Northern Manhattan Study) Neurol. 2010; 75:328-334.

13. Rhoda AJ, Health-related quality of life of patients six months post stroke living in the Western Cape, South Africa, Afri J Disabil. 2014; 3(1): Art. \#126, 6 pages.

14. Lai SM, Studenski S, Duncan PW, Perera S. Persisting consequences of stroke measured by the Stroke Impact Scale. Stroke 2002; 33:1840-1844.

15. Akinpelu A.O., Gbiri C.A. (2009): Quality of life of stroke survivors and apparently healthy individuals in southwestern Nigeria. Physiother. Theory Pract. 25(1), 14-20.

16. Hamzat T.K., Peters G.O. Motor function recovery and quality of life among stroke survivors in Ibadan, Nigeria - A 6-month follow-up study. Eur J Phys Rehabil Med. 2009; 45(2):179-83.

17. Gbiri C.A., Akinpelu A.O., Odole A.C. Prevalence, pattern and impact of depression on quality of life of stroke survivors. Int J Psychiatry Clin Pract. 2010; 14(3): 198-203.

18. Howitt SC, Jones MP, Jusabani A, Gray WK, Aris E, Mugusi F, Swai M, Walker RW A cross-sectional study of quality of life in incident stroke survivors in rural northern Tanzania. J Neurol. $2011 ; 258: 1422-1430$.

19. Akinpelu AO, Gbiri CA, Maruf FA. Quality of Life, Disablement, Comorbidity and Socio-Demographics of Stroke Survivors in South-Western Nigeria. Indian J Physiother Occup Ther 2012; 6 (3):13-18

20. Gbiri CA, Akinpelu A O. Quality of life of Nigerian stroke survivors during first 12 months poststroke. Hong Kong Physiother. J. 2012; 30 (1): $18-24$. 
21. Gbiri CA, Akinpelu A O. Relationship between post-stroke functional recovery and quality of life among Nigerian stroke survivors. Nigerian Postgraduate $M J, 2013$; 20(1): 29-33.

22. Donkor ES, Owolabi MO, Bampoh PO, Amoo PK, Aspelund T, Gudnason V, Profile and health-related quality of life of Ghanaian stroke survivors. Clin Interv Aging. 2014; 9: 1701-1708.

23. Akosile CO, Adegoke B, Ezeife CA, Maruf FA, Ibikunle PO, Johnson OE, Ihudiebube- Splendor C, Dada OO. Quality of life and sex-differences in a south-eastern Nigerian stroke sample. Afr. $J$ Neurol. Sci. 2013; 32 (1).

24. de Haan R, Aaronson N, Limburg M, Hewer RL, van Crevel H. Measuring Quality of Life in Stroke. Stroke. 1993; 24:320-327.

25. Wilson IB, \& Cleary, PD. Linking clinical variables with health-related quality of life. A conceptual model of patient outcomes. JAMA, 1995;273: 59-65.

26. Owolabi MO. Determinants of health-related quality of life in Nigerian stroke survivors. Trans R Soc Trop Med Hyg. 2008; 102(12): 1219-25.

27. Owolabi MO. What are the consistent predictors of generic and specific post- stroke health-related quality of life? Cerebrovasc Dis. 2010; 29(2): 105-10.

28. Owolabi MO. Consistent determinants of poststroke health-related quality of life across diverse cultures: Berlin-Ibadan study. Acta Neurol Scand. 2013; 128(5): 311-20.

29. Hamza AM, Al-Sadat N, Loh SY, Jahan NK. Predictors of Post stroke Health- Related Quality of Life in Nigerian Stroke Survivors: A 1-Year Follow-Up Study. Biomed Res Int. 2014; 350281: pp1-7.

30. Raju RS, Sarma PS, Pandian JD. Psychosocial Problems, Quality of Life, and Functional Independence Among Indian Stroke Survivors. Stroke. 2010; 41: 2932-2937.

31. King RB (1996) Quality of Life After Stroke Stroke. 1996; 27: 1467-1472.

32. Jonsson A, Lindgren I, Hallstrom B, Norrving B, Lindgren A. Determinants of Quality of Life in Stroke Survivors and Their Informal Caregivers Stroke. 2005; 36: 803-808.
33. Kwok T, Lo RS, Wong E, Wai-Kwong T, Mok V, Kai-Sing W. Quality of life of stroke survivors: a 1-year follow-up study. Arch Phys Med Rehabil. 2006; 87(9):1177-82.

34. Teoh V, Sims J, Milgrom J, Psychosocial Predictors of Quality of Life in a Sample of Community-Dwelling Stroke Survivors: A Longitudinal Study. Top Stroke Rehabil. 2009; 16 (2):157-166.

35. Haghgoo HA, Pazuki ES, Hosseini AS, Rassafiani M. Depression, activities of daily living and quality of life in patients with stroke. $J$ Neurol Sci. 2013; 328(1-2):87-91.

36. Schaapsmeerders P, Maaijwee NAM, van Dijk, EJ, Rutten-Jacobs LCA, Arntz RM, Schoonderwaldt HC, Dorresteijn LDA, Kessels RPC, de Leeuw FE. Long-Term Cognitive Impairment After First-Ever Ischemic Stroke in Young Adults. Stroke. 2013; 44:1621-1628.

37. Nys GMS, van Zandvoort MJE, van der Worp HB, de Haan EHF, de Kort PLM, Jansen BPW, Kappelle LJ. Early cognitive impairment predicts long-term depressive symptoms and quality of life after stroke. J Neurol Sci. 2006; 247(2):149-156.

38. Fatoye FO, Komolafe MA, Eegunranti BA, Adewuya AO, Mosaku SK, Fatoye GK. Cognitive impairment and quality of life among stroke survivors in Nigeria. Psychol. Rep. 2007;100: 876-82.

39. Abubakar SA and Isezuo SA. Health related quality of life of stroke survivors: 40 experience of a stroke unit. Int. J Biomed. Sci. 2012; 8(3): 183-187.

40. Assogba K, Belo M, Kombate D, Agbobli A, Apetse K, Kumako V, Guinhouya KM, Balogou AAK, Djassoa G, Grunitzky EK. Quality of life, anxiety and depression in stroke survivors in Togo. Afri J Neurol. Sci. 2011; 30(1).

41. Mackenzie_AE and Chang AM. Predictors of quality of life following stroke. Disabil Rehabil; 2002; 24(5): 259-265.

42. Alaszewski H, Alaszewski A, Potter J, Penhale B and Billings J. Life After Stroke: Reconstructing Everyday Life. A Monograph of the Centre for Health Services Studies, University of Kent. 2014; Access at https://kar.kent.ac.uk/id/eprint/7745

43. Venna VR, Xu Y, Doran SJ, Patrizz A, McCullough LD (2014) Social interaction plays a critical role in neurogenesis and recovery after stroke. Transl Psychiatry. 2014; 4(1). 
44. Levasseur M1, Desrosiers J, Noreau L. Is social participation associated with quality of life of older adults with physical disabilities? Disabil Rehabil. 2004; 26(20): 1206-13.

45. Kruithof WJ1, van Mierlo ML, Visser-Meily JM, van Heugten CM, Post MW. Associations between social support and stroke survivors' health-related quality of life-a systematic review. Patient Educ Couns.2013; 93(2): 169-76.

46. Reblin M and Uchino BN. Social and Emotional Support and its Implication for Health. Curr Opin Psychiatry.2008; 21(2): 201-205.

47. Robinson-Smith G, Johnston MV, Allen J. Selfcare self-efficacy, quality of life, and depression after stroke. Arch Phys Med Rehabil.2000; 81(4):460-4.

48. Owolabi MO. Impact of stroke on health-related quality of life in diverse cultures: the Berlin-Ibadan multicenter international study. Health Qual. Life Outcomes 9:81 http://www.hqlo.com/ content/9/1/81
49. Muli G and Rhoda A. Quality of life amongst young adults with stroke living in Kenya. Afr Health Sci. 2013; 13(3): $632-638$.

\section{Correspondence address:}

Umaru Muhammad BADARU, Department of Physiotherapy, Faculty of College Allied Health Sciences, Bayero University Kano, Nigeria.

Email: badaruum@yahoo.com

Mobile: +2348035913759 